\title{
Acute and Chronic Postsurgical Pain After Living Liver Donation: Incidence and Predictors
}

\author{
Susan Holtzman, ${ }^{1}$ Hance A. Clarke, ${ }^{2,3}$ Stuart A. McCluskey, ${ }^{2,3}$ Kara Turcotte, ${ }^{1}$ David Grant, ${ }^{4}$ \\ and Joel Katz ${ }^{2,3,5}$ \\ ${ }^{1}$ Department of Psychology, University of British Columbia, Kelowna, Canada; ${ }^{2}$ Department of Anesthesia, \\ University of Toronto, Toronto, Canada: ${ }^{3}$ Department of Anesthesia and Pain Management, Toronto \\ General Hospital, Toronto, Canada; ${ }^{4}$ Multiorgan Transplant Program, Toronto General Hospital, University \\ Health Network, University of Toronto, Toronto, Canada; and ${ }^{5}$ Department of Psychology, York University, \\ Toronto, Ontario, Canada
}

Despite its prominence as a concern among potential surgical candidates, there is little information in the literature regarding the short- and long-term pain experience after living liver donation. We undertook a prospective study to examine (1) the nature and incidence of acute and chronic pain after living donor hepatectomy and (2) the factors associated with an increased or decreased risk of adverse pain outcomes. Before donation, a comprehensive assessment of potential predictors of acute and chronic pain outcomes was conducted; this included donors' pain expectations, psychosocial factors, medical histories, and demographic factors. Detailed data regarding pain outcomes were collected postoperatively (days 1 and 2) and again during 6- and 12-month follow-up telephone interviews. Sixty-five adults (32 females and 33 males) scheduled for donor hepatectomy participated. Substantial proportions of the donors reported a moderate-to-severe level of pain intensity ( $\geq 4$ on a $0-10$ scale) at rest and after movement on day 1 ( $42 \%$ and $74 \%$, respectively) and day 2 (33\% and $32 \%$, respectively). Persistent postsurgical pain was reported by $31 \%$ of the donors at the 6 -month follow-up and by $27 \%$ of the donors at the 12-month follow-up. Generally, this pain was mild, and pain-related life interference was minimal. Female sex, a younger age, and several predonation measures of pain-related anxiety were associated with a significantly greater risk of developing persistent postsurgical pain. In conclusion, this study has identified a subset of patients who experience persistent pain after living liver donation. Additional prospective research using larger samples of liver donors is needed to replicate this work, to obtain a more detailed account of the acute and long-term pain experience, and to determine whether targeted interventions can minimize the frequency and severity of chronic pain. Liver Transpl 20:1336-1346, 2014. (c) 2014 AASLD.

Received January 31, 2014; accepted July 2, 2014.

Acute postsurgical pain is an expected outcome after open surgical resection for living liver donation. ${ }^{1-3}$ However, there is accumulating evidence that some living liver donors continue to experience pain beyond the normal expected healing time. ${ }^{4}$ Chronic postsurgical pain (CPSP) is defined as pain lasting more than 2 months after a surgical procedure. ${ }^{5}$ It can negatively affect the overall quality of life, including the ability to return to work after surgery, and it can be extremely costly from a health care perspective. ${ }^{6,7}$ The nature and incidence of CPSP among liver donors remain poorly described and understood, and little is known

\footnotetext{
Abbreviations: APS, acute pain service; ASI, Anxiety Sensitivity Index; CPSP, chronic postsurgical pain; IV, intravenous; NRS, numerical rating scale; PASS-20, Pain Anxiety Symptoms Scale 20; PCA, patient-controlled analgesia; PCEA, patient-controlled epidural analgesia; PCS, Pain Catastrophizing Scale; PDI, Pain Disability Index; SD, standard deviation; SF-36, Short Form 36.

Hance A. Clarke is supported by a merit award from the Department of Anesthesia at the University of Toronto and by the Strategic Training for Advanced Genetic Epidemiology program at the Canadian Institutes of Health Research. Joel Katz is supported as a Canadian Institutes of Health Research Canada Research Chair in Health Psychology at York University.

Potential conflict of interest: Nothing to report.

Address reprint requests to Susan Holtzman, Ph.D., Department of Psychology, University of British Columbia-Okanagan, 3187 University Way, ASC 283, Kelowna, British Columbia, Canada V1V1V7. Telephone: 250-807-8730; E-mail: susan.holtzman@ ubc.ca 
about the factors that may put donors at increased or decreased risk. ${ }^{3,4,8}$

Short- and long-term follow-up studies of liver donors have relied heavily on the Short Form 36 (SF36) to measure pain outcomes. ${ }^{9}$ The SF-36 is a generic measure of health status that includes 2 items about bodily pain (pain severity and life interference due to pain). On the basis of this measurement tool, the mean levels of bodily pain among samples of liver donors have been reported to be as low as, or lower than, those of the general population. ${ }^{4,10,11}$ Although these studies are encouraging, researchers have typically aggregated SF-36 pain scores across donors and thereby obscured a potential subset of donors with chronic pain. The majority of studies have also used cross-sectional designs in which predonation levels of functioning were not assessed; this raises questions about whether postdonation levels of pain and functioning can be solely attributed to the donor surgery (see Verbesey et al., ${ }^{3}$ Chan et al., ${ }^{4}$ and Erim et al. ${ }^{12}$ for exceptions).

In agreement with the broader literature on CPSP, several studies have found that some liver donors do indeed experience prolonged postoperative pain. ${ }^{13}$ For example, in a cross-sectional study of 30 liver donors (median time after donation $=1$ year), 20\% reported ongoing wound pain, but the intensity was not specified. ${ }^{4}$ In a larger cross-sectional study of 83 donors (median time after donation $=69$ months), 6\% reported incisional discomfort requiring regular pain medication, and $2 \%$ reported rib pain that interfered with their daily activities. ${ }^{14}$ In a prospective study of 47 liver donors, the incidence and intensity of surgery-related pain decreased over time; however, 6 months after donation, approximately 6\% reported the pain intensity as "somewhat painful," and 19\% reported it as "not very painful." By 12 months, approximately $17 \%$ reported the continued presence of pain but rated it as "not very painful." 3

In the context of other surgical procedures (eg, hernia repair, thoracotomy, coronary bypass surgery, and limb amputation), systematic literature reviews have suggested that biomedical and demographic factors can play a role in the development and maintenance of CPSP. ${ }^{15-24}$ One of the strongest risk factors for persistent postsurgical pain appears to be pain severity in the first few days after surgery. ${ }^{17}$ Therefore, even though pain is an expected outcome of liver donor surgery, donors who experience high levels of acute postoperative pain may be at a greater risk of developing a persistent pain condition. Psychological factors, including pain-related anxiety and pain catastrophizing, have been linked to higher levels of postoperative pain and to a greater likelihood of transitioning from acute pain to chronic pain. ${ }^{16,25-27}$ Preoperative expectations of high levels of postsurgical pain as well as a more generalized fear of surgery have also been found to predict more intense pain after surgery. ${ }^{28,29}$

In the present study, we used a prospective study design to address questions and concerns related to the pain experience after living liver donation. ${ }^{3,8,27,30}$
The first study aim was to describe the pain experience of donors during the first 2 days after surgery and to compare this to donors' presurgical expectations about postsurgical pain. The second aim was to describe the nature and incidence of persistent postsurgical pain at 6- and 12-month follow-ups. The third and final aim was to explore demographic, surgical, and psychological factors associated with CPSP reported at the 6- and 12-month follow-up interviews.

\section{PATIENTS AND METHODS}

\section{Participants and Recruitment}

Institutional review board approval was obtained (REB 03-0270-AE), and all participants provided informed consent before participation. This prospective study was part of a larger investigation that recruited other surgical populations (eg, lateral thoracotomy, abdominal-gynecological, and orthopedic patients). The present study presents data from adults (18 years old or older) who were scheduled for donor hepatectomy at Toronto General Hospital, a major liver transplantation center located in Toronto, Canada. Donors were recruited for participation during a pre-admission hospital visit approximately 1 week before the donor surgery. The study recruitment and the donor surgeries took place between November 2003 and November 2008. All patients were followed by the acute pain service (APS) managed by the Department of Anesthesia and Pain Management. The APS followed patients with standardized protocols for postoperative pain management, and these protocols remained consistent throughout the data collection period. Patients received either intravenous (IV) patient-controlled analgesia (PCA) or patientcontrolled epidural analgesia (PCEA). Patients with thoracic epidurals placed below the $\mathrm{T} 6$ dermatome received a $0.1 \%$ bupivacaine solution with $0.015 \mathrm{mg} / \mathrm{mL}$ hydromorphone. The epidural infusion was delivered via a Gemstar pump (Abbott, Lake Forrest, IL) at a rate of $5 \mathrm{~mL} /$ hour (with a 3-mL bolus, a 20-minute lockout period, and a 4-hour maximum of $50 \mathrm{~mL}$ ). IV PCA was administered via an Abbot PCA II pump (Abbott, Lake Forrest, IL) with hydromorphone in $0.4 \mathrm{mg} / \mathrm{mL}$ boluses at a dose of 0.2 to $0.4 \mathrm{mg}$ with a 5 -minute lockout period and a 4-hour maximum of $10 \mathrm{mg}$ or with morphine in $1 \mathrm{mg} / \mathrm{mL}$ boluses at a dose of 1.0 to $2.0 \mathrm{mg}$ with a 5-minute lockout period and a 4-hour maximum of $40 \mathrm{mg}$. A standardized algorithm was in place so that the APS physician would adjust the epidural rate or IV PCA settings when necessary to ensure patient comfort. Patients were followed by the APS until the IV PCA or PCEA was discontinued and the patients were switched to oral analgesia (narcotics and low-dose acetaminophen). The APS reviewed analgesics again before patient discharge.

\section{Procedure}

Data for the present study were collected at 4 time points: (1) preoperatively, (2) postoperatively (days 1 
and 2), (3) at a 6-month follow-up, and (4) at a 12month follow-up. Preoperatively, during the preadmission hospital visit approximately 1 week before the donor surgery, participants completed a set of written questionnaires assessing their expectations for postsurgical pain, psychosocial factors (trait anxiety, pain anxiety, anxiety sensitivity, and pain catastrophizing), medical history, and demographic factors. Approximately 24 and 48 hours after the surgery, donors reported their pain intensity scores at rest and after a standardized movement. Six and 12 months after the surgery, participants took part in telephone interviews that focused on the details of any ongoing pain problems that they had experienced as a result of the donor surgery.

\section{Attrition}

Eighty donors agreed to participate in this study: 3 had their surgeries cancelled, 2 surgeries were rescheduled (without the researchers being notified), and 10 donors did not provide sufficient data to be included in the analyses. Two of those with insufficient data withdrew themselves from the study before the surgery, 3 withdrew themselves after the surgery (but before the postoperative pain assessment on day 1), 1 withdrew between the day 1 and day 2 postoperative pain assessments, 1 did not complete the baseline questionnaires or the postdischarge follow-up interviews, and 3 were excluded because, although they consented to participate, they did not complete any of the study measurements. In all, 65 donors responded to preoperative questions regarding their pain expectancies, medical history, and demographics, and 57 of those 65 donors $(87.7 \%)$ completed the preoperative psychosocial questionnaires. Postoperatively, 63 donors (96.9\%) responded to pain-related questions. Fifty-five of the 65 donors $(84.6 \%)$ took part in the 6-month follow-up telephone interview, and 52 of the 65 donors (80\%), including 6 who could not be reached at 6 months, took part in the 12-month follow-up interview. Donors who failed to complete the 6- and/or 12-month follow-up did not differ significantly in age, sex, or postoperative pain levels at 24 and 48 hours from those who completed the 6- and 12-month follow-up interviews (all $P$ values $>0.15)$.

\section{Measures}

\section{Preoperative Assessment}

Pain-Related and Demographic Variables. Participants were asked to rate the pain intensity and pain unpleasantness that they expected to experience after donor surgery with an 11-point numerical rating scale (NRS) ranging from 0 (no pain) to 10 (worst possible pain). The NRS is a brief, easy-to-use pain assessment tool that has demonstrated strong reliability and validity in previous studies of acute and chronic pain patients (including surgical populations). ${ }^{31-33}$ Participants were also asked a series of detailed questions about past surgeries and pain conditions as well as any ongoing pain problems (for more information on this questionnaire, see Pagé et $a{ }^{34}{ }^{34}$. Lastly, a variety of demographic factors (eg, age, ethnicity, and employment status) were assessed.

Psychosocial Variables. Participants also completed a set of standardized measures of psychological factors (pain disability, trait anxiety, pain anxiety, anxiety sensitivity, and pain catastrophizing) that have been shown to be predictive of acute and chronic postoperative pain. These measures have shown strong reliability and validity in studies of surgical patients and those with acute and chronic pain. ${ }^{25,35,36}$ In the current study, Cronbach's $\alpha$ was strong for the total and subscale scores of all measures (ranging from 0.75 to 0.95), with the exception of the social concerns subscale of the Anxiety Sensitivity Index (ASI; 0.52) and the magnification subscale for the Pain Catastrophizing Scale (PCS; 0.53). The details of these measures are outlined next.

Pain disability was measured with the Pain Disability Index (PDI), which is a 7-item scale assessing the degree to which pain interferes with 7 life domains (family/home responsibilities, recreation, social activity, occupation, sexual behavior, self-care, and lifesupport activity). ${ }^{37}$

Trait anxiety (the stable tendency to experience frequent state anxiety) was assessed with the 20-item trait subscale of the Spielberger State-Trait Anxiety Inventory. ${ }^{38}$

Pain-related anxiety was assessed with the Pain Anxiety Symptoms Scale 20 (PASS-20), a 20-item measure designed to assess fear and anxiety responses to pain. ${ }^{39}$ The PASS-20 consists of four 5item scales measuring cognitive anxiety, escape and avoidance responses, fearful thinking, and physiological anxiety responses.

Anxiety sensitivity was assessed with the ASI, a 16item measure of the degree to which individuals fear cognitive or somatic symptoms of anxiety because of a belief that these symptoms may be dangerous or harmful. ${ }^{40}$ The ASI comprises 1 higher order factor (the ASI total score) and 3 lower order factors: the fear of physical symptoms of anxiety, the fear of losing mental control, and the fear of looking nervous to others. ${ }^{41}$

Pain catastrophizing was assessed with the PCS, a 13-item scale that measures catastrophic thinking related to pain. ${ }^{42}$ Participants reflect on past painful experiences and indicate the degree to which they experience a variety of thoughts and feelings. The PCS provides a total score and 3 subscale scores assessing pain rumination, magnification, and helplessness.

\section{Postsurgical Assessment}

Approximately 24 and 48 hours after the surgery, participants were asked to rate their present pain intensity at rest and after a standardized movement with an 11-point NRS ranging from 0 (no pain) to 10 
TABLE 1. Sample Characteristics Before Donor Surgery

\begin{tabular}{|c|c|}
\hline Sex: female [n (\%)] & $32(49.2)$ \\
\hline Age (years)* & $38.7 \pm 11.8(20-59)$ \\
\hline Ethnicity: Caucasian [n (\%)] & $57(87.7)$ \\
\hline \multicolumn{2}{|l|}{ Education [n (\%)] } \\
\hline Less than high school & $1(1.5)$ \\
\hline High school degree & $21(32.3)$ \\
\hline University or college degree & 37 (56.9) \\
\hline Graduate degree & $6(9.2)$ \\
\hline Currently employed [n (\%)] & $56(86.2)$ \\
\hline Body mass index $\left(\mathrm{kg} / \mathrm{m}^{2}\right)^{*}$ & $\begin{array}{r}25.1 \pm 3.5 \\
(18.7-34.1)\end{array}$ \\
\hline Ongoing pain problem [n (\%)] & $11(16.9)$ \\
\hline $\begin{array}{l}\text { Average pain intensity } \\
\text { (when in pain)* }\end{array}$ & $5.6 \pm 3.3(1-10)$ \\
\hline $\begin{array}{l}\text { Pain-related disability } \\
\text { (PDI)* }\end{array}$ & $8.6 \pm 14.5(0-46)$ \\
\hline \multicolumn{2}{|l|}{$\begin{array}{l}\text { Life interference due } \\
\text { to pain (n) }\end{array}$} \\
\hline Not at all & \\
\hline Slightly & 3 \\
\hline Moderately & 4 \\
\hline Severe & \\
\hline
\end{tabular}

*The data are presented as means and SDs (with ranges in parentheses).

(worst possible pain), with the endpoints representing the most extreme pain experiences. The assessment of movement-evoked pain involved having the patient sit up in bed from a lying position and then provide a pain rating. This is a common method for assessing movement-evoked pain after surgery in the abdominal area. ${ }^{43}$ Pain ratings were obtained at approximately the same time of day (between 2 and $4 \mathrm{PM}$ ) by research nurses who were dedicated solely to working on research projects and who were trained in the pain assessment methods used here. NRS ratings $\geq 4$ were considered to be in the moderate-to-severe range. ${ }^{44}$

\section{6- and 12-Month Follow-Up Assessments}

Telephone interviews were conducted 6 and 12 months after the surgery to assess pain related to the donor hepatectomy. Using an NRS [ranging from 0 (no pain) to 10 (worse possible pain)], donors were asked to recall, at its worst, how intense and unpleasant the pain was after their operation and to indicate how long it took for their surgical pain to go away completely. Those donors who reported that they were still experiencing pain due to surgery were asked about the nature of this pain (eg, present pain intensity, frequency, location, and pain-related life interference) and if they had returned to work or to regular activities since the operation. ${ }^{34}$ Donors also completed the PDI during the 6- and 12-month interviews. ${ }^{37}$

\section{RESULTS}

\section{Sample Characteristics}

A detailed description of the demographic and medical characteristics of the sample is provided in Table 1. The final sample comprised 65 liver donors (32 females and 33 males) with a mean age of 38.7 years [standard deviation $(\mathrm{SD})=11.8$, range $=20-59$ years $]$ at the time of donation. The majority of the sample was Caucasian $(87.7 \%)$ and had at least a high school education (98.5\%). Before the donor surgery, 11 donors (16.9\%) reported an ongoing pain problem (defined as pain lasting longer than 1 month). The diagnosis and location of this pain varied widely and included neck or back pain $(n=3)$, arthritis $(n=2)$, leg pain $(n=3)$, headaches $(n=1)$, and a rotator cuff tear $(n=1)$. Notably, none reported preoperative pain at the site of the proposed incision. The standard incision for living liver donors at our institution is a subcostal incision. The majority of the participants (66.7\%) underwent left donor hepatectomy, and the remainder underwent right donor hepatectomy. Most donors (60.3\%) received IV PCA, 36.5\% received PCEA, and 3.2\% received both IV PCA and PCEA. Complications in the present sample were graded according to the revised Clavien classification system. ${ }^{45}$ Sixty donors $(92.3 \%)$ had at least 1 in-hospital grade I complication, with the most common being nausea (75.4\%), pruritus (53.8\%), vomiting (38.5\%), gas pain (18.5\%), headache (15.4\%), and dizziness $(12.3 \%)$. For the majority of the donors $(75 \%)$, these were mild in severity. Donors' symptoms resolved before discharge with the exception of 1 donor who had mild constipation. Lastly, 7 donors (10.8\%) had a grade II or higher complication while they were in the hospital (urinary retention requiring recatheterization, $\mathrm{n}=5$; bilateral pleural effusion, $\mathrm{n}=1$; or pulmonary embolism, $\mathrm{n}=1$ ).

\section{Postoperative Pain Expectancies and Outcomes}

Donors' expected and actual postoperative pain intensity ratings are presented in Fig. 1. Before donation, donors expected a mean postoperative pain intensity of $7.9(\mathrm{SD}=1.8)$ and a mean postoperative pain unpleasantness of $7.6(\mathrm{SD}=1.8)$. However, on day 1 after the surgery, the mean pain intensity ratings at rest and after movement were $3.2(\mathrm{SD}=2.2)$ and $5.4(\mathrm{SD}=2.5)$, respectively. On day 2 , the mean pain intensity ratings at rest and after movement were $2.7(\mathrm{SD}=2.1)$ and $4.8(\mathrm{SD}=2.5)$, respectively. At the 6-month interview, donors' retrospective reports of their worst pain intensity and pain unpleasantness since surgery were $7.3 \quad(\mathrm{SD}=2.5)$ and $7.0(\mathrm{SD}=2.6)$, respectively. At 12 months, the retrospective reports of the worst pain intensity and unpleasantness since surgery were $7.1 \quad(\mathrm{SD}=2.2)$ and $6.7(\mathrm{SD}=2.3)$, respectively. The results of a repeated measures analysis of variance revealed a statistically significant difference between donors' presurgical pain intensity expectations and donors' actual postsurgical pain intensity ratings [days 1 and 


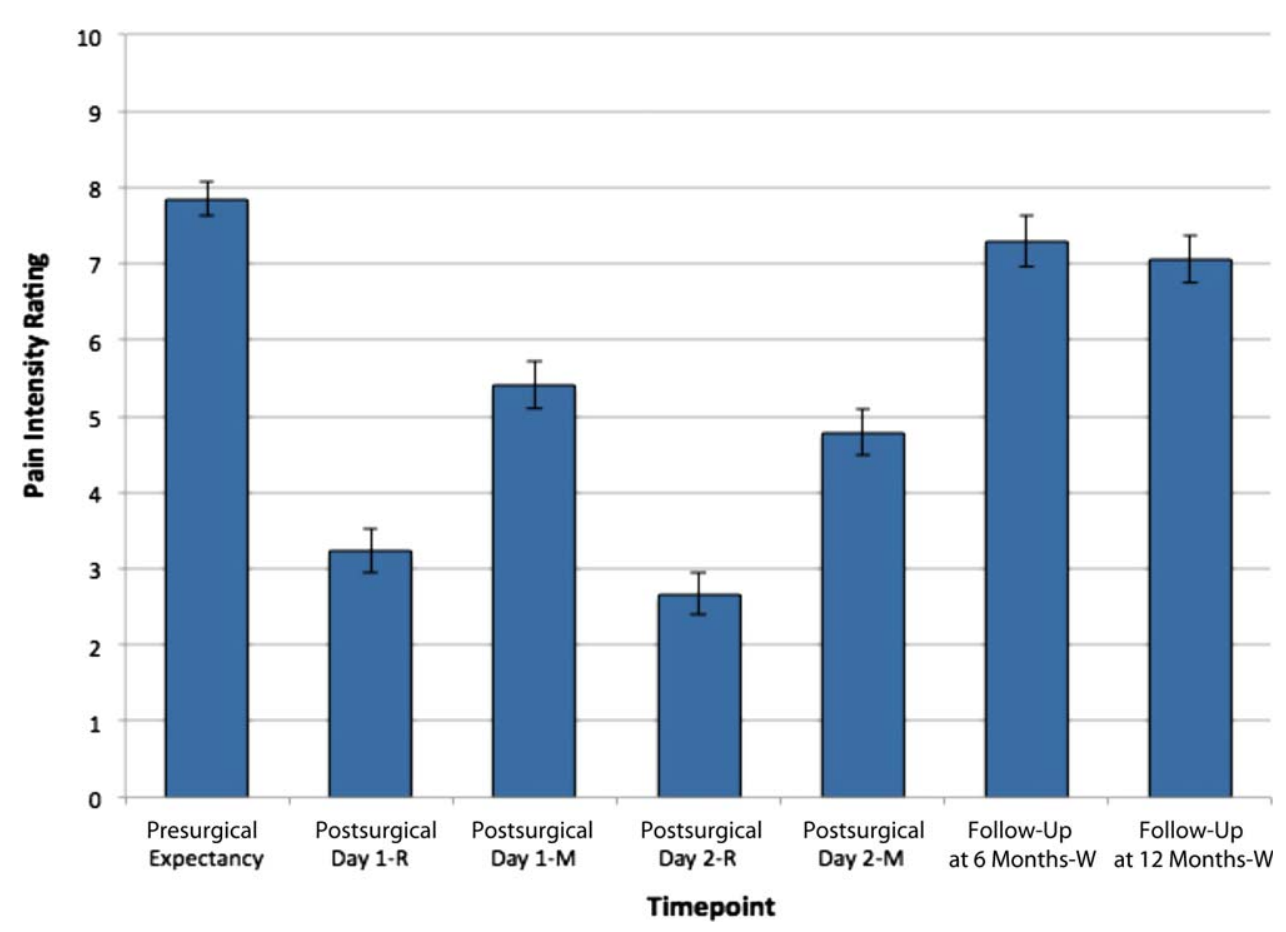

Figure 1. Pain following living liver donation: predonation expectancies and postdonation pain ratings. Data are presented as means and standard errors of the mean. The sample sizes for each time point are as follows: before surgery, $\mathrm{n}=65$; day 1 after surgery, $\mathrm{n}=62$; day 2 after surgery, $\mathrm{n}=63 ; 6$-month follow-up, $\mathrm{n}=55$; and 12-month follow-up, $\mathrm{n}=52$. Presurgical expectancies for postsurgical pain were obtained approximately 1 week before surgery. $\mathrm{R}$ indicates pain intensity at rest, $\mathrm{M}$ indicates pain intensity after standardized movement, and $\mathrm{W}$ indicates the recollection of the worst pain since surgery.

2 after surgery and recall of worst pain at 6 and 12 months; $F(6)=49.2, P<0.001]$. Post hoc analyses indicated that donors' expectancies for postdonation pain intensity were significantly higher than donors' actual postdonation ratings of pain intensity (all $P$ values $<0.05$ ). It is important to note that, although expectancies for postdonation pain were statistically higher than donors' 6- and 12-month recollections of their worst pain, the difference was small and below the 2-point difference required to be clinically meaningful. ${ }^{46}$

\section{Pain Outcomes at the 6- and 12-Month Follow- Up Interviews}

At the 6-month follow-up interview, donors reported that their surgical pain had completely gone away within several days $(n=1), 1$ to 2 weeks $(n=8), 3$ to 4 weeks ( $n=10), 5$ to 8 weeks $(n=9)$, or 3 to 4 months $(\mathrm{n}=11)$ after surgery. Details regarding the cases of persistent postsurgical pain at 6 and 12 months are provided in Table 2. At the 6-month follow-up interview, 17 donors $(30.9 \%)$ reported that they were still experiencing pain related to their donor surgery. Three of the 17 donors reported an average pain level in the moderate-to-severe range. Eight of the 17 donors who were still experiencing pain at 6 months reported ongoing pain at 12 months, 7 reported that their pain had gone away completely by 12 months, and 2 failed to complete the 12-month follow-up interview.
At the 12-month follow-up interview, 14 donors reported experiencing persistent postsurgical pain [ie, the 8 who reported pain at 6 months plus another 6 donors ( 3 of whom had said their surgical pain had gone away at the 6-month interview and 3 who had not completed the 6-month follow-up interview, so their pain status at that time is unknown)]. Among the 14 donors (26.9\%) who were still experiencing pain at 12 months, 5 reported pain in the moderate-to-severe range.

\section{Factors Associated With Postoperative and Persistent Pain After Donor Surgery}

A series of bivariate analyses (independent sample $t$ tests and chi-square tests) were conducted to explore factors related to postsurgical pain intensity (aggregated across days 1 and 2) and the presence (yes/no) of CPSP at the 6- and 12-month follow-ups. The following factors were examined: psychosocial factors (predonation expectancies for postsurgical pain and pain unpleasantness, pain anxiety, pain catastrophizing, anxiety sensitivity, and trait anxiety), medical factors (body mass index, ongoing pain problem and pain-related disability before donation, IV PCA versus PCEA, right versus left hepatectomy, and Clavien grade I and II in-hospital complications), and demographic factors (age and sex). When we were testing predictors of CPSP, the following additional factors were explored: postsurgical pain intensity (at rest and movement-evoked) and retrospective recall of the worst pain intensity and unpleasantness since 
TABLE 2. Description of Living Liver Donors Who Continued to Experience Pain 6 and/or 12 Months After the Donor Surgery

\begin{tabular}{|c|c|c|}
\hline & 6-Month Follow-Up (n=17) & 12-Month Follow-Up $(\mathrm{n}=14)$ \\
\hline \multirow[t]{4}{*}{ Location of pain* } & Abdomen $(n=6)$ & Abdomen $(n=2)$ \\
\hline & Incision site $(n=8)$ & Incision site $(\mathrm{n}=8)$ \\
\hline & Under/around rib cage $(n=2)$ & Back $(n=1)$ \\
\hline & Right side $(\mathrm{n}=1)$ & Right side $(\mathrm{n}=5)$ \\
\hline \multirow[t]{3}{*}{ Pain frequency } & Constant $(n=4)$ & Constant $(\mathrm{n}=3)$ \\
\hline & Periodic $(\mathrm{n}=8)^{\dagger}$ & Periodic $(\mathrm{n}=4)^{\S}$ \\
\hline & Brief $(n=5)^{\ddagger}$ & Brief $(n=7)^{\|}$ \\
\hline Average pain intensity ${ }^{\mathrm{TI}}$ & $2.8 \pm 2.2(1-8)$ & $2.9 \pm 1.4(1-5)$ \\
\hline Average pain unpleasantness ${ }^{\mathrm{II}}$ & $2.8 \pm 2.1(0-8)$ & $2.2 \pm 1.3(0-5)$ \\
\hline $\mathrm{PDI}^{\mathrm{II}}$ & $6.5 \pm 11.7(0-37)$ & $5.9 \pm 8.6(0-27)$ \\
\hline \multirow{4}{*}{ Life interference due to pain } & Not at all $(n=9)$ & Not at all $(\mathrm{n}=7)$ \\
\hline & Slightly $(\mathrm{n}=6)$ & Slightly $(\mathrm{n}=3)$ \\
\hline & Moderately $(\mathrm{n}=1)$ & Moderately $(n=4)$ \\
\hline & Severely $(\mathrm{n}=1)$ & \\
\hline \multirow{4}{*}{ Returned to work or regular activities } & Yes $(n=14)$ & Yes $(n=11)$ \\
\hline & Yes with modified & Yes with modified \\
\hline & responsibilities $(n=1)$ & responsibilities $(\mathrm{n}=2)$ \\
\hline & No $(n=2)$ & No $(\mathrm{n}=1)$ \\
\hline \multirow[t]{2}{*}{ Ongoing pain problem before donation } & Yes $(n=4)$ & Yes $(n=0)$ \\
\hline & No $(\mathrm{n}=13)$ & No $(n=14)$ \\
\hline \multicolumn{3}{|c|}{$\begin{array}{l}\text { NOTE: Pain intensity and pain unpleasantness were scored on a possible scale of } 0 \text { to } 10 \text {, and pain disability was scored } \\
\text { on a possible scale of } 0 \text { to } 70 \text {, with higher scores reflecting worse functioning. } \\
\text { *Some donors reported more than } 1 \text { pain location. } \\
\text { 'Donors described this periodic pain as occurring more than once a day }(n=1) \text {, daily }(n=1) \text {, more than once a week } \\
(n=2) \text {, or weekly }(n=4) \text {. } \\
\text { fDonors described this brief pain as occurring more than once per week }(n=2) \text { or weekly }(n=3) \text {. } \\
\text { } \text { Donors described this periodic pain as occurring daily }(n=2) \text {, more than once per week }(n=1) \text {, or weekly }(n=1) \text {. } \\
\text { "Donors described this brief pain as occurring daily }(n=1) \text {, more than once per week }(n=3) \text {, weekly }(n=1) \text {, or monthly } \\
(n=2) \text {. } \\
\text { II The data are presented as means and SDs (with ranges in parentheses). }\end{array}$} \\
\hline
\end{tabular}

surgery (provided during the 6- and 12-month interviews). Because of the exploratory nature of these analyses and our goal of avoiding type II errors (in order to identify candidate variables for further research), factors that were related to pain outcomes at $P<0.10$ were considered statistically significant. As a result, findings should be interpreted with caution, particularly because of the large number of comparisons that were conducted.

\section{Postoperative Pain (Rest)}

Younger donors reported significantly greater levels of postoperative pain at rest $[r(64)=-0.26, P=0.04]$. The use of PCEA (versus IV PCA) was associated with lower postoperative pain at rest $[t(58)=1.79$, $P=0.08]$. Donors with an ongoing pain problem before surgery also reported lower postoperative pain intensity at rest than those who did not report an ongoing pain problem $[t(62)=-1.75, P=0.09]$.

\section{Postoperative Pain (Movement-Evoked)}

Younger donors reported greater levels of movementevoked pain $[r(64)=-0.22, P=0.08]$. Donors who reported greater expectations for pain unpleasantness $[r(64)=0.27, P=0.03]$ and who scored higher on the PASS-20 cognitive anxiety subscale $[r(56)=0.31$, $P=0.02]$ and the PASS-20 total scale score $[r(56)=0.22, P=0.098]$ reported greater movementevoked pain intensity. Lastly, higher scores on the PCS magnification subscale were associated with higher levels of movement-evoked pain $[r(56)=0.24$, $P=0.07]$.

\section{Persistent Pain (6-Month Follow-Up)}

Female donors were significantly more likely to report persistent postsurgical pain at the 6-month follow-up $\left[\chi^{2}(1)=5.37, P=0.02\right.$ (relative risk $=2.68,95 \%$ conference interval =1.09-6.58)]. In fact, 12 of the 17 donors $(71 \%)$ who reported persistent pain at 6 months were female. Greater postoperative pain intensity at rest and after movement (averaged across days 1 and 2) was not associated with a greater risk of persistent pain $[t(53)=1.52, P=0.14$ (Cohen's $d=0.42$ ) for rest; $t(53)=0.72, P=0.48$ (Cohen's $d=0.20$ )] for movement. However, during the 6-month interview, donors who recalled a higher worst level of pain intensity after surgery were significantly more likely to 
report persistent pain at the 6-month follow-up $[t(53)=3.05, P=0.004$ (Cohen's $d=0.84)]$.

\section{Persistent Pain (12-Month Follow-Up)}

Female sex was also related to persistent pain at 12 months: 10 of the 14 donors $(71 \%)$ with persistent pain were female $\left[\chi^{2}(1)=2.92, \quad P=0.09\right.$ (relative risk $=2.32, \quad 95 \%$ conference interval $=0.83-6.45)]$. Donors who scored higher on the social concerns subscale of the ASI were more likely to report persistent pain at the 12-month follow-up $[t(42)=2.84$, $P=0.007$ (Cohen's $d=0.88$ )]. Lastly, donors who recalled a significantly worse level of pain unpleasantness (during the 12-month interview) were more likely to report CPSP $[t(50)=2.28, \quad P=0.03 \quad$ (Cohen's $d=0.64)$ ]. Recollections of the worst pain intensity were not significantly related to CPSP $[t(50)=1.62$, $P=0.11$ (Cohen's $d=0.46)$ ].

\section{DISCUSSION}

The present prospective study represents the most comprehensive examination of pain outcomes among liver donors to date. On average, donors reported a mild level of pain intensity (at rest) during the first 2 days after their surgery. However, a closer examination of the data reveals that a substantial proportion of the donors experienced moderate-to-severe levels of acute postsurgical pain (defined as an NRS pain intensity score of 4 or more). ${ }^{44}$ On day 1 , the proportions of donors who reported moderate-to-severe pain were $41.9 \%$ (at rest) and $74.2 \%$ (after movement), and on day 2, the proportions were $33.3 \%$ (at rest) and $31.7 \%$ (after movement). The majority of the donors reported a complete resolution of postsurgical pain within 6 months or 1 year, and this is in line with previous research. ${ }^{3,4,8}$ However, in agreement with our hypotheses, we found that 17 of the 55 donors (30.9\%) who completed the 6-month follow-up interview reported CPSP, and 14 of the 52 donors (26.9\%) reported CPSP at the 12-month follow-up. Although we did not formally assess the possibility that the postoperative pain was a continuation of an existing pain problem, ${ }^{5}$ it is notable that for none of the patients who reported preoperative pain was its location at the site of the proposed incision. The prevalence rates of CPSP after other abdominal surgeries (eg, open cholecystectomy, hysterectomy, and hernia repair) vary widely from $5 \%$ to more than $50 \% .^{17,18,47-49}$ This variability is due to a number of factors, including the specific type of surgery/incision, intraoperative nerve damage, the duration of surgery, the timing of follow-up, the method of pain assessment, and the minimum pain score required for classification as chronic pain-positive. ${ }^{17,18}$ Although it is difficult to draw a direct comparison, the CPSP rates for our sample of living liver donors do fall within the range for other major abdominal surgeries.

It is important to point out that the intensity of CPSP was mild for most donors. Moreover, the major- ity of donors with CPSP described the frequency of their pain as brief and/or periodic, and they reported that pain-related disability was generally absent or minimal. Three donors (at the 6-month follow-up) and 5 donors (at the 12-month follow-up) reported persistent postsurgical pain in the moderate-to-severe range, and these incidence rates (5.5\% and 9.6\%) are consistent with previous studies of living liver donors. $^{3,14}$ All 5 of these donors indicated that their CPSP was "not at all" interfering with their life. This may reflect the careful screening process that occurs before donation to ensure that prospective donors are emotionally and physically high-functioning.

Two demographic factors emerged as important predictors of pain outcomes in this study of living liver donors: age and sex. Younger donors were more likely to report higher levels of acute postoperative pain, and this is consistent with a number of previous studies of other surgical procedures. ${ }^{50,51}$ Several explanations for this, including a decrease in peripheral nociceptive functioning with increasing age, have been proposed. ${ }^{52}$ In predicting CPSP, age was no longer a significant factor. Indeed, there continues to be some controversy about whether younger age is associated with a greater risk of developing CPSP. In contrast, acute levels of postoperative pain were not significantly different between male and female donors; however, females were more than 2 times more likely to report CPSP at the 6- and 12-month follow-up in comparison with males. The finding that $71 \%$ of those with CPSP were women is consistent with a large body of research showing a greater prevalence of chronic pain conditions among women. ${ }^{20}$ A number of studies have found higher levels of postoperative pain in women versus men. ${ }^{20,21}$ However, research regarding sex differences in postoperative pain has been equivocal. ${ }^{20,50}$ Sex differences in acute and chronic pain likely arise from a number of complex and interacting biological, psychological, and social mechanisms. ${ }^{53,54}$ Clearly, one would not want to rule out prospective donors because they were young or female. However, the present findings do suggest that there may be room for improvement in the treatment of acute postoperative pain of younger donors and a need for measures to address the elevated risk for CPSP among female liver donors. The lack of an association between donor complications and pain outcomes is also noteworthy. This may have been due to the fact that the vast majority of the complications were mild and transient in nature (eg, nausea and pruritus), and this does not exclude the possibility that surgical complications can put donors at risk for adverse pain outcomes. ${ }^{17,18}$

Several anxiety-related factors were also associated with pain outcomes. Donors who reported a predonation tendency to respond to pain with fear and anxiety and, in particular, with higher levels of cognitive anxiety (eg, worry and rumination) reported significantly more intense postoperative pain after standardized movement. A tendency to experience exaggerated negative thoughts and feelings about pain (eg, fearing that pain might get worse) was also associated with 
greater postoperative pain intensity. The only other anxiety factor that was associated with pain outcomes was the social concerns subscale of the ASI, which was related to a greater likelihood of CPSP at the 12month follow-up. More general levels of trait anxiety (Spielberger State-Trait Anxiety Inventory) and anxiety sensitivity were not related to any donor pain outcomes. These mixed findings mirror the broader literature regarding anxiety as a risk factor for CPSP. There is evidence that preoperative (pain-specific and general) anxiety confers a risk for CPSP, but there is variability across studies regarding which specific scales and subscales are most important. ${ }^{55-58}$

The role of predonation expectancies regarding acute postsurgical pain and CPSP was also explored. In the present study, donors who expected greater pain unpleasantness reported significantly greater movement-evoked pain on days 1 and 2 after surgery. However, expectancies for postsurgical pain intensity and pain unpleasantness did not affect the likelihood of developing CPSP. Our results also revealed a striking discrepancy between expected and actual pain outcomes, such that donors expected a significantly higher level of postsurgical pain (7.85 on the 0-10 NRS) than they actually reported on days 1 and 2 after surgery. On one hand, this may reflect a true disconnect between donors' expected and actual pain outcomes. Indeed, a previous study of 226 liver donors at our center found that the average pain intensity reported at $6 \mathrm{PM}$ and midnight on the day of surgery was less than 4 on the 0 to $10 \mathrm{NRS}^{1}{ }^{1}$ On the other hand, donors' pain ratings on days 1 and 2 after surgery may represent an underestimate of the acute pain experience. ${ }^{59}$ For example, donors in the current study were asked to report their present pain at 24 hours, not their worst pain over the past 24 hours. It is also possible that some donors may have underreported their pain to put on a brave face for their health care team and their recipients.

Donors' preoperative pain expectancies were much closer to the worst level of pain that they reported since donation (when they were queried during the 6and 12-month follow-up interviews). However, because of the way these follow-up questions were worded, we cannot pinpoint exactly when donors experienced their worst pain after donation (eg, during the first hours or days in the hospital or after discharge). It is also difficult to tease apart whether the higher pain reports at 6 and 12 months are accurate recollections or whether these recollections may reflect a retrospective recall bias or a preoperative expectancy bias. ${ }^{60}$ The fact that donors (on average) expected such a high level of pain intensity is interesting because living liver donors at our center take part in a discussion of pain and pain modalities during the preadmission hospital visit, during which most are informed that they will likely experience a mild-tomoderate level of pain intensity after the surgery.

One possibility raised by our findings is that the 6and 12-month reports are in fact accurate and that pain becomes more intense once donors are discharged from the APS and/or hospital because they no longer have access to the superior in-hospital pain control regimen (eg, PCEA and IV PCA). This is clearly supported by the literature for other surgical procedures (eg, total knee arthroplasty). ${ }^{61}$ Prospective data on the intensity of acute pain in the hours after surgery and during the initial days and weeks after patients have been discharged home are needed to ascertain the extent to which the discrepancies between actual pain and expected pain are accurate or are due to recall bias. A prospective examination of different pain trajectories among donors [eg, those who experience constant pain (pain at 6 and 12 months) and those who experience decreasing pain (pain at 6 months but not at 12 months)] and predictors of these trajectories is also warranted. Nevertheless, among those who continued to report pain at the 6- and 12-month follow-ups, the extent to which the pain interfered with everyday activities was low for most donors (see Table 2).

The present study has a number of limitations. First, the relatively small sample size may have hindered our statistical power to identify risk factors for acute and persistent postsurgical pain. We used a more liberal criterion for statistical significance to address this issue, but this may have led to a greater likelihood of a type II error. We also tested a large number of candidate predictors of pain outcomes. This inclusive approach was employed because of the challenges of obtaining detailed prospective data on liver donors. Second, the generalizability of these findings to other liver donor populations is yet to be determined, particularly because this study was limited to a single center. The main focus of the present study was the incidence and predictors of postoperative pain and CPSP. Therefore, it is possible that there may have been a self-selection bias by which donors with more pain were more likely to participate in the follow-up interviews. However, the finding that donors who completed the 6- and 12-month follow-up interviews did not differ significantly from those who did not in terms of their pain scores on postoperative days 1 and day 2 suggests that this was not the case. Third, there may be other donor-specific psychosocial factors (eg, stress and depression) as well as centerspecific factors that are associated with donor pain outcomes that we did not assess in the present study. ${ }^{21}$ Fourth, the reliability of 2 of the anxiety subscales (social concerns of the ASI and magnification of the PCS) was low. Thus, even though they were predictors of pain outcomes, these findings should be interpreted with caution. Similarly, because of the large number of statistical comparisons, findings need to be replicated in future research. Fifth, postoperative pain assessment was limited to 2 time points (days 1 and 2), and because PCA is the standard of care at our center, this may have introduced some additional variability into the postoperative pain data. By focusing on the first 48 hours after surgery, we also may not have captured the pain experience 
during important transitions, such as increases in mobility (eg, hallway walking) and the transition to oral analgesics. Lastly, 36.5\% of our sample received PCEA. The use of epidurals in the adult living liver donor population has decreased at many centers (and they are no longer being used at our institution) because of concerns about the risk of epidural hematoma. Thus, the acute pain profile reported in this study may actually be worse today than when these data were collected. Our previous retrospective study showing that, in comparison with IV PCA, PCEA provides superior pain relief during the first 3 days after living liver donation supports this suggestion. ${ }^{23}$ Currently, our center is evaluating the use of medial open transversus abdominis plane catheters to better manage pain after open liver resection as an alternative to PCEA and IV PCA (Karanicolas et al.). ${ }^{62}$

Understanding and improving pain outcomes among living liver donors has been identified as a key priority by liver transplant clinicians and researchers and is a current focus of the National Institutes of Healthfunded Adult-to-Adult Living Donor Liver Transplantation Cohort Study. ${ }^{1,23,63,64}$ The use of a prospective design in the present study allowed for unique insights into pain outcomes, and it suggests that there continues to be room for improvement in the management of pain after donor hepatectomy. At least one-third of the donors reported moderate-to-severe pain at rest on days 1 and 2 after surgery, and more than one-quarter of the donors indicated the presence of persistent postsurgical pain at the 6- and 12month follow-ups (although life interference due to pain was minimal). Findings from the present study indicate that donors who are younger, are female, and report pain-related anxiety are at higher risk of developing CPSP. By targeting and intervening with these at-risk individuals, we may be able to improve shortand long-term pain outcomes. A recent randomized controlled trial showed that a brief psychological intervention before surgery improved many outcomes after living liver donation, including pain at 3 months. ${ }^{65}$ More generally, donors may benefit from a greater focus on pain management during discharge planning and, in particular, on addressing barriers to effective pain management in the home (eg, undesirable side effects and underprescribing).

\section{ACKNOWLEDGMENT}

The authors thank Eileen Halket for her assistance with the data collection and management and Brittany Boorman and Courtney Boyer for their editorial assistance with this article.

\section{REFERENCES}

1. Clarke H, Chandy T, Srinivas C, Ladak S, Okubo N, Mitsakakis N, et al. Epidural analgesia provides better pain management after live liver donation: a retrospective study. Liver Transpl 2011;17:315-323.

2. Cywinski JB, Parker BM, Xu M, Irefin SA. A comparison of postoperative pain control in patients after right lobe donor hepatectomy and major hepatic resection for tumor. Anesth Analg 2004;99:1747-1752.

3. Verbesey JE, Simpson MA, Pomposelli JJ, Richman E, Bracken AM, Garrigan K, et al. Living donor adult liver transplantation: a longitudinal study of the donor's quality of life. Am J Transplant 2005;5:2770-2777.

4. Chan SC, Liu CL, Lo CM, Lam BK, Lee EW, Fan ST. Donor quality of life before and after adult-to-adult right liver live donor liver transplantation. Liver Transpl 2006; 12:1529-1536.

5. Macrae WA, Davies HTO. Chronic postsurgical pain. In: Crombie IK, Croft PR, Linton SJ, LeResche L, Von Korff M, eds. Epidemiology of Pain. Seattle, WA: IASP Press; 1999:125-142.

6. Northup PG, Abecassis MM, Englesbe MJ, Emond JC, Lee VD, Stukenborg GJ, et al.; for Adult-to-Adult Living Donor Liver Transplantation Cohort Study Group. Addition of adult-to-adult living donation to liver transplant programs improves survival but at an increased cost. Liver Transpl 2009;15:148-162.

7. Parsons B, Schaefer C, Mann R, Sadosky A, Daniel S, Nalamachu S, et al. Economic and humanistic burden of post-trauma and post-surgical neuropathic pain among adults in the United States. J Pain Res 2013;17: 459-469.

8. Parikh ND, Ladner D, Abecassis M, Butt Z. Quality of life for donors after living donor liver transplantation: a review of the literature. Liver Transpl 2010;16:13521358.

9. Ware JE Jr, Sherbourne CD. The MOS 36-item ShortForm Health Survey (SF-36). I. Conceptual framework and item selection. Med Care 1992;30:473-483.

10. DuBay DA, Holtzman S, Adcock L, Abbey S, Greenwood $\mathrm{S}$, Macleod C, et al. Adult right-lobe living liver donors: quality of life, attitudes and predictors of donor outcomes. Am J Transplant 2009;9:1169-1178.

11. Takada Y, Suzukamo Y, Oike F, Egawa H, Morita S, Fukuhara S, et al. Long-term quality of life of donors after living donor liver transplantation. Liver Transpl 2012;18:1343-1352.

12. Erim Y, Beckmann M, Kroencke S, Valentin-Gamazo C, Malago M, Broering D, et al. Psychological strain in urgent indications for living donor liver transplantation. Liver Transpl 2007;13:886-895.

13. Ishizaki M, Kaibori M, Matsui K, Kwon AH. Change in donor quality of life after living donor liver transplantation surgery: a single-institution experience. Transplant Proc 2012;44:344-346.

14. Sotiropoulos GC, Radtke A, Molmenti EP, Schroeder T, Baba HA, Frilling A, et al. Long-term follow-up after right hepatectomy for adult living donation and attitudes toward the procedure. Ann Surg 2011;254:694-700.

15. Katz J. One man's risk factor is another man's outcome: difference in risk factor profiles for chronic postsurgical pain maintenance vs transition. Pain 2012;153:505-506.

16. VanDenKerkhof EG, Peters ML, Bruce J. Chronic pain after surgery: time for standardization? A framework to establish core risk factor and outcome domains for epidemiological studies. Clin J Pain 2013;29:2-8.

17. Katz J, Seltzer Z. Transition from acute to chronic postsurgical pain: risk factors and protective factors. Expert Rev Neurother 2009;9:723-744.

18. Kehlet H, Jensen TS, Woolf CJ. Persistent postsurgical pain: risk factors and prevention. Lancet 2006;367: 1618-1625.

19. Katz J, Clarke H, Seltzer Z. Review article: preventive analgesia: quo vadimus? Anesth Analg 2011;113:12421253.

20. Fillingim RB, King CD, Ribeiro-Dasilva MC, RahimWilliams B, Riley JL III. Sex, gender, and pain: a review 
of recent clinical and experimental findings. J Pain 2009; 10:447-485.

21. Hinrichs-Rocker A, Schulz K, Järvinen I, Lefering R, Simanski C, Neugebauer EA. Psychosocial predictors and correlates for chronic post-surgical pain (CPSP)-a systematic review. Eur J Pain 2009; 13:719-730.

22. Andreae MH, Andreae DA. Local anaesthetics and regional anaesthesia for preventing chronic pain after surgery. Cochrane Database Syst Rev 2012;10: CD007105.

23. Clarke H, Bonin RP, Orser BA, Englesakis M, Wijeysundera DN, Katz J. The prevention of chronic postsurgical pain using gabapentin and pregabalin: a combined systematic review and meta-analysis. Anesth Analg 2012;115:428-442.

24. Jones C, Kelliher L, Dickinson M, Riga A, Worthington T, Scott MJ, et al. Randomized clinical trial on enhanced recovery versus standard care following open liver resection. Br J Surg 2013;100:1015-1024.

25. Kleiman V, Clarke H, Katz J. Sensitivity to pain traumatization: a higher-order factor underlying pain-related anxiety, pain catastrophizing and anxiety sensitivity among patients scheduled for major surgery. Pain Res Manag 2011;16:169-177.

26. Lautenbacher S, Huber C, Schöfer D, Kunz M, Parthum A, Weber PG, et al. Attentional and emotional mechanisms related to pain as predictors of chronic postoperative pain: a comparison with other psychological and physiological predictors. Pain 2010;151:722-731.

27. Lee SH, Lim KC, Jeon MK, Kim IO, Jeong JS, Hong JJ, Ha HS. Postoperative pain and influencing factors among living liver donors. Transplant Proc 2012;44:363-365.

28. Logan DE, Rose JB. Gender differences in post-operative pain and patient controlled analgesia use among adolescent surgical patients. Pain 2004;109:481-487.

29. Sommer M, de Rijke JM, van Kleef M, Kessels AG, Peters ML, Geurts JW, et al. Predictors of acute postoperative pain after elective surgery. Clin J Pain 2010;26:87-94.

30. Lee SH, Jeong JS, Ha HS, No MJ, Hong JJ, Kwon JS, et al. Decision-related factors and attitudes toward donation in living related liver transplantation: ten-year experience. Transplant Proc 2005;37:1081-1084.

31. Ferreira-Valente MA, Pais-Ribeiro JL, Jensen MP. Validity of four pain intensity rating scales. Pain 2011;152:23992404.

32. Gagliese L, Weizblit N, Ellis W, Chan VW. The measurement of postoperative pain: a comparison of intensity scales in younger and older surgical patients. Pain 2005; 117:412-420.

33. Jensen MP, Karoly P, Braver S. The measurement of clinical pain intensity: a comparison of six methods. Pain 1986;27:117-126.

34. Pagé GM, Kleiman V, Asmundson GJ, Katz J. Structure of posttraumatic stress disorder symptoms in pain and pain-free patients scheduled for major surgery. J Pain 2009;10:984-991.

35. Coons MJ, Hadjistavropoulos HD, Asmundson GJ. Factor structure and psychometric properties of the Pain Anxiety Symptoms Scale-20 in a community physiotherapy clinic sample. Eur J Pain 2004;8:511-516.

36. Schnur JB, Hallquist MN, Bovbjerg DH, Silverstein JH, Stojceska A, Montgomery GH. Predictors of expectancies for post-surgical pain and fatigue in breast cancer surgical patients. Pers Individ Dif 2007;42:419-429.

37. Pollard CA. Preliminary validity study of the Pain Disability Index. Percept Mot Skills 1984;59:974.

38. Spielberger CD, Gorsuch RL, Lushene PR, Vagg PR, Jacobs AG. State-Trait Anxiety Inventory (Form Y). Palo Alto, CA: Consulting Psychologists Press; 1983.
39. McCracken LM, Dhingra L. A short version of the Pain Anxiety Symptoms Scale (PASS-20): preliminary development and validity. Pain Res Manag 2002;7:45-50.

40. Reiss S, Peterson RA, Gursky DM, McNally RJ. Anxiety sensitivity, anxiety frequency and the prediction of fearfulness. Behav Res Ther 1986;24:1-8.

41. Zinbarg RE, Barlow DH, Brown TA. Hierarchical structure and general factor saturation of the Anxiety Sensitivity Index: evidence and implications. Psychol Assess 1997;9:277-284.

42. Sullivan MJL, Bishop SR, Pivik J. The Pain Catastrophizing Scale: development and validation. Psychol Assess 1995; 7:524-532.

43. Srikandarajah S, Gilron I. Systematic review of movement-evoked pain versus pain at rest in postsurgical clinical trials and meta-analyses: a fundamental distinction requiring standardized measurement. Pain 2011;152:1734-1739.

44. Gerbershagen HJ, Rothaug J, Kalkman CJ, Meissner W. Determination of moderate-to-severe postoperative pain on the numeric rating scale: a cut-off point analysis applying four different methods. Br J Anaesth 2011;107: 619-626.

45. Dindo D, Demartines N, Clavien PA. Classification of surgical complications: a new proposal with evaluation in a cohort of 6336 patients and results of a survey. Ann Surg 2004;240:205-213.

46. Farrar JT, Young JP Jr, LaMoreaux L, Werth JL, Poole RM. Clinical importance of changes in chronic pain intensity measured on an 11-point numerical pain rating scale. Pain 2001;94:149-158.

47. Borly L, Anderson IB, Bardram L, Christensen E, Sehested A, Kehlet $\mathrm{H}$, et al. Preoperative prediction model of outcome after cholecystectomy for symptomatic gallstones. Scand J Gastroenterol 1999;34:11441152 .

48. Massaron S, Bona S, Fumagalli U, Battafarano F, Elmore U, Rosati R. Analysis of post-surgical pain after inguinal hernia repair: a prospective study of 1,440 operations. Hernia 2007; 11:517-525.

49. Pinto PR, McIntyre T, Nogueira-Silva C, Almeida A, Araújo-Soares V. Risk factors for persistent postsurgical pain in women undergoing hysterectomy due to benign causes: a prospective predictive study. J Pain 2012;13: 1045-1057.

50. Ip HY, Abrishami A, Peng PW, Wong J, Chung F. Predictors of postoperative pain and analgesic consumption: a qualitative systematic review. Anesthesiology 2009;111: 657-677.

51. Macrae WA. Chronic post-surgical pain: 10 years on. $\mathrm{Br}$ J Anaesth 2008;101:77-86.

52. Perry F, Parker RK, White PF, Clifford PA. Role of psychological factors in postoperative pain control and recovery with patient-controlled analgesia. Clin J Pain 1994;10: 57-63.

53. Martin AL, Halket E, Asmundson GJ, Flora DB, Katz J. Posttraumatic stress symptoms and the diathesis-stress model of chronic pain and disability in patients undergoing major surgery. Clin J Pain 2010;26:518-527.

54. Turk DC. A diathesis-stress model of chronic pain and disability following traumatic injury. Pain Res Manag 2002;7:9-19.

55. Pritchard MJ. Identifying and assessing anxiety in preoperative patients. Nurs Stand 2009;23:35-40.

56. Sullivan M, Tanzer M, Stanish W, Fallaha M, Keefe FJ, Simmonds M, Dunbar M. Psychological determinants of problematic outcomes following total knee arthroplasty. Pain 2009; 143:123-129.

57. Sullivan M, Tanzer M, Reardon G, Amirault D, Dunbar $\mathrm{M}$, Stanish W. The role of presurgical expectancies in 
predicting pain and function one year following total knee arthroplasty. Pain 2011;152:2287-2293.

58. Theunissen M, Peters ML, Bruce J, Gramke HF, Marcus MA. Preoperative anxiety and catastrophizing: a systematic review and meta-analysis of the association with chronic postsurgical pain. Clin J Pain 2012;28:819-841.

59. Ko JS, Choi SJ, Gwak MS, Kim GS, Ahn HJ, Kim JA, et al. Intrathecal morphine combined with intravenous patient-controlled analgesia is an effective and safe method for immediate postoperative pain control in live liver donors. Liver Transpl 2009;15:381-389.

60. Redelmeier DA, Katz J, Kahneman D. Memories of colonoscopy: a randomized trial. Pain 2003;104:187-194.

61. Chan EY, Blyth FM, Nairn L, Fransen M. Acute postoperative pain following hospital discharge after total knee arthroplasty. Osteoarthritis Cartilage 2013;21:1257-1263.

62. Karanicolas P, Cleary S, McHardy P, McCluskey S, Sawyer J, Ladak S, Law C, Wei A, Coburn N, Ko R, Katz J, Kiss A, Khan J, Coimbatore S, Lam-McCulloch J,
Clarke H. Medial open transversus abdominis plane (MOTAP) catheters for analgesia following open liver resection: study protocol for a randomized controlled trial. Trials.

63. Mandell MS, Pomfret EA, Steadman R, Hirose R, Reich DJ, Schumann R, Walia A. Director of anesthesiology for liver transplantation: existing practices and recommendations by the United Network for Organ Sharing. Liver Transpl 2013;19:425-430.

64. Schumann R, Mandell MS, Mercaldo N, Michaels D, Robertson A, Banerjee A, et al. Anesthesia for liver transplantation in United States academic centers: intraoperative practice. J Clin Anesth 2013;25:542550.

65. Dew MA, DiMartini AF, DeVito Dabbs AJ, Zuckoff A, Tan HP, McNulty ML, et al. Preventative interaction for living donor psychosocial outcomes: feasibility and efficacy in a randomized controlled trial. Am J Transplant 2013;13: 2672-2684 